\title{
Kas-iskelet sistemi enfeksiyonlarında kullanılan antibiyotikler ve özellikleri
}

\section{Antibiotics used in musculoskeletal infections and their properties}

\author{
Nevres Hürriyet Aydoğan, Cem Yalın Kılınç \\ Muğla Sıtkı Koçman Üniversitesi Tıp Fakültesi, Ortopedi ve Travmatoloji Anabilim Dalı, Muğla
}

\begin{abstract}
Bu makaledeki amacımız ortopedik enfeksiyonlarda sık kullanılan antibiyotiklerin özellikleri ve kullanımları hakkında bilgi vermektir. Ortopedik cerrahi hastalarında ameliyat sonrası süreçte enfeksiyon sıklıkla görülebilir ve önlenebilir bir komplikasyondur. Ortopedik enfeksiyonlar artmış finansal, psikososyal problemleri de beraberinde getirir ve önemli bir morbidite nedenidir. Patolojinin olduğu bölgeye göre enfeksiyona neden olan suş ve tedavisi değişebilir. Ayrıca enfeksiyon normal ortopedik seyri bozarak tedavi sürecini olumsuz etkiler. Total diz ve kalça artroplastileri sonrası enfeksiyon oranları \%1 ile $\% 5$ arasındadır. Ortopedik travma sonrası enfeksiyon görülme oranı ise \%5 ile \%10 arasında değişmektedir. Özellikle giderek artan dirençli bakteri suşları tedaviyi olumsuz olarak etkilemektedir. Bu durumda uzun süreli antibiyoterapi veya kombine antibiyotik rejimlerine ihtiyaç duyulabilir. Medikal dergi veya kitaplarda yayımlanmış ortopedik enfeksiyonlar ve bu enfeksiyonlara dair antibiyoterapi sunan makaleler taranmıştır. İncelenen makale ve kitap bölümleri total eklem artroplastisi, ayakayakbileği, omuz-dirsek, travma, spor cerrahisi, el cerrahisi ve pediatrik ortopedi ile ilgili enfeksiyonları içermektedir. Ortopedik onkoloji enfeksiyonları ile ilgili makaleler çalışma dışı bırakıldı. Kas-iskelet sistemi enfeksiyonlarında giderek artan antibiyotik direnci bulunmaktadır. Direnç varlığında antibiyotik kombinasyonlarının kullanılması gerekebilmektedir. Antibiyotik direnci uygun antibiyotik seçimi ve bu antibiyotiğe direnç gelişmeyecek şekilde kullanımı gerektirmektedir.
\end{abstract}

Anahtar sözcükler: kas-iskelet sistemi enfeksiyonları; antibiyotikler; ortopedik enfeksiyonlar

\begin{abstract}
We aim to provide information regarding the properties and use of antibiotics that are frequently used to treat orthopedic infections. Infection is a preventable complication that is frequently observed in patients undergoing orthopedic surgery during the postoperative period. Orthopedic infections lead to increased financial and psychosocial problems and are a significant cause of morbidity. Depending on the area and the pathological condition, the strain that causes the infection and the treatment to be administered may change. In addition, infections negatively affect the treatment process by disrupting the normal orthopedic progress. The rate of infection after total knee and hip arthroplasties varies between $1 \%$ and $5 \%$, whereas that after an orthopedic trauma varies between $5 \%$ and $10 \%$. The treatment is negatively affected, particularly due to the increasing number of resistant bacterial strains. Therefore, it may be necessary to administer long-term antibiotherapy or combination antibiotic regimens in such cases. Papers and published medical journals or books on orthopedic infections and the use of antibiotherapy in such infections were reviewed. The reviewed papers and book sections contained infections associated with total joint arthroplasty, sports surgery, trauma, and pediatric orthopedics as well as leg-ankle, shoulder-elbow, and hand infections. Papers on infections in orthopedic oncology were excluded. The antibiotic resistance in musculoskeletal infections is increasing, requiring the selection of a suitable antibiotic and its use in such a way that does not induce resistance to the antibiotic. In addition, the use of combination antibiotic therapy in patients with antibiotic resistance may be required.
\end{abstract}

Key words: musculoskeletal infections; antibiotics; orthopedic infections

Patolojinin olduğu bölgeye göre enfeksiyona neden olan suş ve tedavisi değişebilir. Ayrıca enfeksiyon normal ortopedik seyri bozarak tedavi sürecini olumsuz etkiler.

Total diz ve kalça artroplastileri sonrası enfeksiyon oranları \%1 ile 5 arasındadır. ${ }^{[3-4]}$ Ortopedik travma sonrası enfeksiyon görülme oranı ise $\% 5$ ile 10 arasında

- İletişim adresi: Doç. Dr. Cem Yalın Kılınç, Muğla Sıtkı Koçman Üniversitesi Tıp Fakültesi, Ortopedi ve Travmatoloji Anabilim Dalı, Muğla Tel: 0505 - 2549719 e-posta: cykilinc@gmail.com

- Geliș tarihi: 5 Haziran $2020 \quad$ Kabul tarihi: 1 Temmuz 2020 


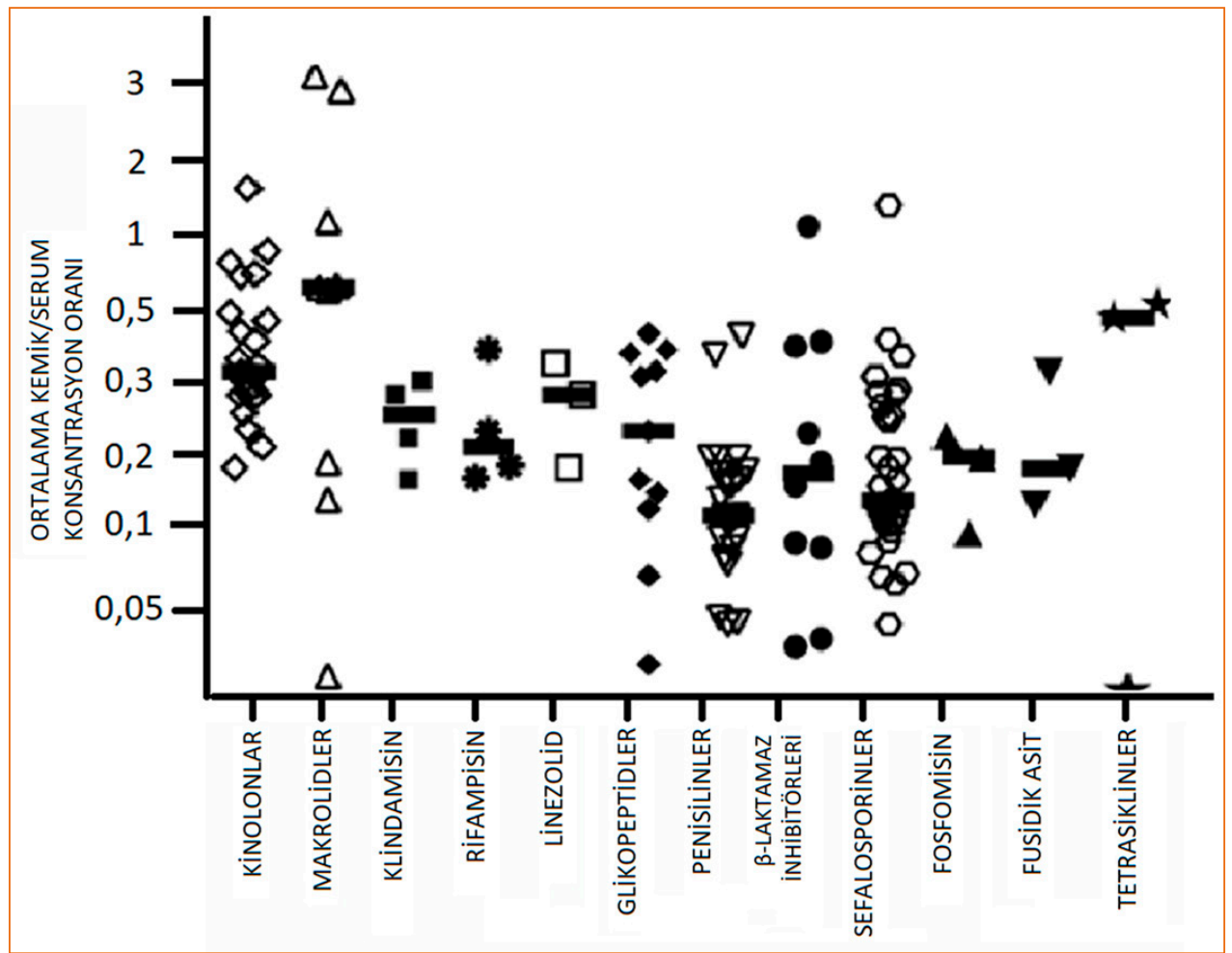

Şekil 1. Farklı antibiyotik gruplarının kemik penetrasyonu. ${ }^{[6]}$

değişmektedir. ${ }^{[5]}$ Özellikle giderek artan dirençli bakteri suşları tedaviyi olumsuz olarak etkilemektedir. Bu durumda uzun süreli antibiyoterapi veya kombine antibiyotik rejimlerine ihtiyaç duyulabilir. ${ }^{[4]}$ Bu makaledeki amacımız ortopedi ve travmatoloji alanındaki enfeksiyonlarda sık kullanılan antibiyotiklerin özellikleri ve kullanımları hakkında bilgi vermektir. Medikal dergi veya kitaplarda yayımlanmış ortopedik enfeksiyonlar ve bu enfeksiyonlara dair antibiyoterapi sunan makaleler taranmıştır. İncelenen makale ve kitap bölümleri total eklem artroplastisi, ayak-ayakbileği, omuz-dirsek, travma, spor cerrahisi, el cerrahisi ve pediatrik ortopedi ile ilgili enfeksiyonları içermektedir. Ortopedik onkoloji enfeksiyonları ile ilgili makaleler çalışma dışı bırakıldı. Ortopedik enfeksiyonlar ile ilgili 145 makale taranarak bu makalelerden hangi antibiyotiğin nasıl kullanıldığı ile ilgili olan 38 tanesi seçilerek incelendi.

\section{ANTIBIYYOTIKLERIN KEMIK PENETRASYONU}

Farklı antibiyotik grupları için kemik penetrasyonu Şekil 1'de gösterilmiştir. ${ }^{[6]}$ Her sembol, bir klinik çalışmada ortalama kemik/serum veya kemik/plazma konsantrasyon oranını temsil eder. Genel olarak; amoksisilin, piperasillin/tazobaktam, kloksasillin, sefalosporinler, karbapenemler, aztreonam, aminoglikozitler, florokinolonlar, doksisiklin, vankomisin, linezolid, daptomisin, klindamisin, trimetoprim/sulfametoksazol, fosfomisin, rifampin iyi kemik penetrasyonu göstermektedir. ${ }^{[7]}$

\section{ANTIBIYOTIK GRUPLARI}

\section{Penisilinler ve $\beta$-Laktamaz İnhibitörleri}

Penisilinler sıklıkla kas-iskelet sistemi enfeksiyonlarında kullanılmaktadır. Sıklıkla penisilin G'nin prokain veya benzatin ile kombine edildiği depo formları kullanılır. Penisilin grubu antibiyotikler özellikle; S.pyogenes, S.agalacttiaeve, C.perfringens'e karşı etkilidir. Ayrıca B. fragilis gibi anaerob bakterilere karşı da etkindir. Ancak S.pneumoniae penisiline karşı \%15 orta, \%15 yüksek direnç göstermektedir. ${ }^{[8]}$

Penisilin kullanımı ile anafilaksi görülebilmektedir. ${ }^{[9]}$ Penisilin kullanan hastalarda \%1-5 oranında ürtiker ve \%1-9 oranında döküntüler görülebilir. Ayrıca değişik serilerde coombs pozitif hemolitik anemi, santral sinir sistemi toksisitesi (epileptik atak) ve böbrek yetmezliği bildirilmiştir. ${ }^{[10]}$ 
Penisilinaz rezistan pensilinler: metisilin, nafsilin, izoksazol penisilinler (oksasilin, kloksasilin, dikloksasilin, flukloksasilin) olarak sınıflanabilir. Metisilin duyarIı S.aureus, S. pyogenes ve S.pneumoniae'ya karşı kullanılır. Gram (-) basillere ve Enterekok türlerine karşı etkinlikleri yoktur. Metisilin, nafsilin ve oksasilin; interstisyel nefrit, lökopeni ve geri dönüşümlü karaciğer fonsiyon bozukluğu yapabilir. [11]

Önemli bazı aminopenisilinler ampisilin esterleri (bakampisilin, pivampisilin, talampisilin), amoksisilin, hetasilin, siklasilin ve episilinler olarak gruplandırılabilir. Enterekok türleri (E.faecalis, E.faecium) ve önemli bazı gram (-) suşlara (E.coli, P.mirabilis) karşı etkili tedavi sağlar. ${ }^{[12]}$ Aminopenisilinler rubella benzeri deri döküntülerine neden olabilir. ${ }^{[8]}$

Karboksipensilinler (tikarsilin, karbenisilin) geniş spektrumlu penisilinler grubundadır. Özellikle antipsödomonal olarak etkilidir. Ayrıca Enterobakter türleri, Serratia türleri ve B.fragilis'e karşı da etkilidir. ${ }^{[8]}$ Yan etki olarak sodyum düşüklüğü, trombosit fonksiyon bozukluğu ve kanamaya neden olabilir.

Asilüreido penisilinler (mezlosilin, azlosilin, piperasilin) yine geniş spekturumlu pensilinler grubundandır. Antibakteriyel spektrumları tikarsilin gibidir. Tikarsiline oranla H.influenzae ve B.fragilis'e karşı daha etkilidir. ${ }^{[8]}$

$\beta$-laktamaz; bakterilerden salınan ve dirence neden olan bir tür eksoenzimdir. Klavulanikasid, sulbaktam ve tazobaktam $\beta$-laktamaz üretimini bloke eder. Özellikle S.aureus ve S.epidermidis'e karşı oldukça etkilidir. ${ }^{[8]}$ Gram (-) bakterilerden de E.coli, Klebsiella ve Bacteroides türlerine karşı etkilidir. Yan etki olarak diğer penisilin türleri ile benzerlik gösterir.

\section{Diğer $\boldsymbol{\beta}$-laktam Antibiyotikler}

Aztreonam bir monosiklik $\beta$-laktam antibiyotik olup özellikle Enterobacter ve P.aeruginosa'ya karşı etkilidir. ${ }^{[13]}$ Aztreonam aerobik gram (+) veya anaerobik bakterilere karşı kayda değer bir antibakteriyel aktiviteye sahiptir. İlacın paranteral uygulanması gerekmektedir. Bu antibiyotikle önemli bir advers reaksiyonlar bildirilmemiştir. ${ }^{[13]}$ Bulantı, kusma ve karaciğer enzimlerinde yükselmeye neden olabilir. .

İmipenem; $\beta$-laktam antibiyotik sınıfına ait bir antimikrobiyal ajandır. Biyokimyasal olarak bir karbopenemdir. Aerob gram (+) bakterilere karşı in vitro aktivitesi oldukça yüksektir. S.aureus, S.epidermidis ve streptekok türlerine karşı oldukça etkilidir. Ayrıca Enterobacter, P.aeruginosa gibi gram (-) bakterilere ve B.fragilis gibi birçok anaerob bakteri türüne karşı da etkilidir. ${ }^{[8]}$ Yan etki olarak bulantı, kusma ve ishal oluşturabilir. Penisilin ile çapraz alerjik reaksiyon oluşturabilir. Bu antibiyotiği alan hastaların \%1-4'ünde jeneralize tonik-klonik nöbetler görülebilir.

\section{Sefalosporinler}

Sefalosporinler birinci, ikinci, üçüncü ve dördüncü nesil ajanlara ayrılmıştır. Birinci nesil sefalosporinler; sefaleksin, sefalotin, sefasetril, sefadoksil ve sefazolin olup özellikle S.aureus, S.epidermidis, ve streptokok türlerine karşı etkilidir. Sefolosporinlerde sınırlı gram (-) aktivite bulunur. Ancak E.coli, Klebsiella türleri ve P.mirabilis'e karşı etkilidir. ${ }^{[8]}$ ilk nesil sefalosporinler güvenli antibiyotikler olsa da bazen alerjik reaksiyonlar, ilaç reaksiyonları, flebit ve ishal tablosu oluşturabilir.

Sefazolin stafilokokların neden olduğu osteomiyelit ve benzeri hastalıklarda ilk tercihtir. Diğer birinci nesil sefalosporinlere göre daha uzun bir yarı ömür ve daha yüksek serum konsantrasyonuna sahiptir. ${ }^{[14]}$

İkinci jenerasyon sefalosporinler 1. jenerasyonlara oranla gram (-) etkinliği fazla, 3. jenerasyonlara göre azdır. 2. nesile örnek olarak sefamandol, sefoksitin, sefiroksim, sefotetan verilebilir. Sefotetan ve sefoksitin gram (-)'lere özellikle de B.fragilis'e karşı oldukça etkilidir. ${ }^{[8]}$

Majör 3. nesil sefolosporinler; sefotaksim, seftriakson, seftizoksim, sefoperazon ve seftazidim olarak sayılabilir. 3. nesil, 1. nesille karşılaştıııldığında gram $(+)$ etkinliği daha azdır. Ancak enterobaktere karşı oldukça etkilidir. Seftazidim etkinlik olarak diğer 3. jenerasyonlar gibidir ancak P.aeruginosa'ya karşı oldukça etkilidir. ${ }^{[15]}$ Sıklıkla P.aeruginosa enfeksiyonlarında aminoglikozitler ile kombine edilerek kullanılır. ${ }^{[15]}$

Dördüncü nesil sefalosporinler sefepim ile temsil edilir. Sefepim aerobik gram $(+)$ organizmalara (metisiline duyarlı S.aureus dahil) ve gram (-) organizmalara (P.aeruginosa dahil) karşı mükemmel aktiviteye sahiptir. ${ }^{[8]}$

Penisilin alerjisi olan hastaların sefalosporin grubu antibiyotik kullanmaları durumunda \%3-7'sinde çapraz alerjik reaksiyon meydana gelebilmektedir. Tedaviye başlandıktan sonra üç veya beş gün sonra tip 1 alerjik reaksiyon, bronkospazm ve deri döküntüleri şeklinde alerjik reaksiyonlar görülebilir. Az sayıda hastada ateş, eozinofili, lenfadenopati, $\% 3$ hastada coombs pozitif anemi, \%1 hastada nötropeni yapabilir. ${ }^{[8]}$

\section{Glikopeptitler}

Glikopeptitler; vankomisin ve daha sonra geliştirilen teikoplaninden oluşur. Vankomisin; S.aureus, S.epidermidis ve enterokok türlerine karşı oldukça etkilidir. Penisilin ve sefolosporin türlerinin etki etmediği hastalarda tercih edilen antibiyotik grubudur. ${ }^{[16]}$ Vankomisin aynı zamanda metisiline dirençli S.aureus 
ve koagülaz negatif stafilokok türlerinin tedavisi için tercih edilen antibiyotiktir. Metisiline duyarlı stafilokok enfeksiyonları tedavisinde kullanılmamalıdır. Stafilokok enfeksiyonlarında tedavi başarısız olursa rifampin ve/veya gentamisinle kombinasyon tercih edilmelidir. Metisiline dirençli stafilokokların yüksek oranda bulunduğu protez implant cerrahisi yapılan merkezlerde kısa süreli profilakside tercih edilebilir. Ancak enterekok türleri başta olmak üzere S.haemolyticus ve L.monocytogenes kökenlerinde vankomisine direnç saptanmıştır. Özellikle vankomisine dirençli enterokoklar giderek artan oranda etken olarak ortaya çıkmakta ve hastane enfeksiyonları salgınları oluşturabilmektedir. Bu diğer bakterilere aktarılabilecek plazmid kaynaklı bir dirençtir. ${ }^{[17]}$

Teikoplaninin etki spekturumu vankomisine benzer. Streptokoklara ve enterokoklara etkinliği daha iyidir. Tedavi süresinde direnç gelişimi olabileceği hatırlanmalıdır. ${ }^{[8]}$

Vankomisinin geliştirilen daha saf preparatlarında yan etki daha az saptanmaktadır. Ototoksisite doza bağımlıdır. Tinnitus ve yüksek tonlarda işitme kaybı ile başlayarak ilerler. Kalıcı ve ilerleyici olabilir. Nefrotoksisite özellikle diğer nefrotoksik ilaçlarla (aminoglikozid, etakrinik asit) beraber kullanıldığında ortaya çıkmaktadır. ${ }^{[17]}$ Özellikle infüzyon sırasında lokal hiperosmolariteye bağlı histamin yanıtı nedeniyle oluştuğu düşünülen 'kırmızı adam' (redman - flushing) sendromu gelişebilir. ${ }^{[8]}$ Bunlardan başka flebit sık rastlanan (\%13) bir yan etkidir. Ateş, titreme ve makülopapüler döküntü olabilir. Nötropeni ve trombositopeniye yol açabilir. ${ }^{[8]}$

\section{Klindamisin}

Klindamisin klinik olarak anaerobik bakterilere karşı en aktif antibiyotiklerden biridir, Özellikle B.fragilis, S.aureus, koagülaz negatif stafilokok türleri ve streptekok türlerine karşı etkilidir. Ancak klostridal türlere karşı etkisizdir.

Klindamisin kemiğe oldukça iyi nüfuz eder, abse içine yayılımı da oldukça iyidir. ${ }^{[18]}$ Klindamisin çok toksik değildir. Ancak hastaların \%8 kadarında diyare, pseudomemranos colit oluşturabilir. ${ }^{[18]}$

\section{Makrolitler}

Eritromisin makrolit grubunun prototipini oluşturur. ${ }^{[19]}$ Bakteri ribozomları üzerinden etki gösterir ve bakteriostatiktir. İ vitro olarak özellikle streptekok türleri, L.monositogenes, M.catarhalis, M.pneumonia, L.pneumophila ve C.pneumonia'ya karşı etkilidir. Yeni grup makrolitler (klaritromisin, azitromisin) düşük konsantrasyonlarda M.pneumonia, Legionella türleri ve
C.pneumonia'ya karşı etkilidir. ${ }^{[19]}$ Ayrıca H.influenzae, M.aviumintracellulare ve diğer atipik mikobakter türlerine karşı etkilidir. Makrolitler özellikle alt ve üst solunum yolları enfeksiyonları ile cilt enfeksiyonlarına karşı etkilidir.

Makrolitler yan etki olarak oldukça güvenilir antibiyotikler olarak bilinir. Hastaların yaklaşık \%20'sinde gastrointestinal reaksiyonlara, bulantı, kusma ve karında kramplara yol açabilir. ${ }^{[8]}$

\section{Tetrasiklinler}

Tetrasiklinler etki sürelerine göre kısa etkili (klortetrasiklin, oksitetrasiklin, tetrasiklin), orta etkili (demoklosiklin) ve uzun etkili (doksisiklin ve minosiklin) olarak sınıflanabilir. Tetrasiklinler bakteriostatiktir. ${ }^{[8]}$ Yararlı ilaçlar olup özellikle nadir görülen bruselloz ve granüloma inguinale tedavisinde kullanılır. Minosiklin oldukça aktif bir tetrasiklin türü olup stafilokokus aureus enfeksiyonlarında kullanılabilir. Ayrıca oral yoldan minosiklin ve rifampin kombinasyonu metisilin rezistan S.aureus ve koagülaz negatif stafilokok türlerinin tedavisinde kullanılabilir.

Tetrasiklinler yağ doku içinde iyi yayılım gösterdiği için dokulara dağılımı oldukça iyidir. Yağ içinde çözülümü en iyi olan minosiklindir. Tetrasiklinler kemiklerde birikir. ${ }^{[8]}$

Yan etkileri bulantı, kusma, ishal ve anoreksidir. On iki yaşından küçük çocuklara verilmez. Verildiği taktirde kemik gelişiminde bozulma ve dişlerde kahverengi renk değişimine neden olabilir.

\section{Oksazolidinon}

Sentetik antibiyotik grubundandır. Bazı önemli bakteriyel suşlar için bakteriyositatik aktiviteye sahiptir. ${ }^{[20]}$ Özellikle metisilin dirençli S.aureus, penisilin dirençli S.pneumonia ve metisilin dirençli enterekok türlerinde kullanılır. ${ }^{[20]}$ Yan etkileri; dilde renk değişikliği, folikülit benzeri döküntü, bulantı, kusma ve ishaldir.

\section{Aminoglikozitler}

Aminoglikozitler; gentamisin, tobramisin, amikasin, netilmisin ve streptomisin gibi alt gruplardan oluşur. Aerobik gram (-) bakterilere karşı etkilidirler. Gram $(+)$ bakterilere karşı belirgin bir etkinliği yoktur. ${ }^{[21]}$ S.aureus tedavisinde kullanılabilir ancak çok hızlı direnç gelişebilmektedir.[21] Gentamisin ciddi MRSA enfeksiyonlarında vankomisin ile, ciddi enterokok enfeksiyonlarında (sepsis, endokardit) ampisilin ya da vankomisin ile kombine olarak kullanılabilirler. Streptekok türlerine karşı bir etkinliği yoktur. Enterobacteriaceae ve P.aeruginosa'ya karşı oldukça etkilidir. P.aeruginosa'nın 
etken olduğu ciddi enfeksiyonlarda mutlaka tedaviye eklenmeleri gerekir.

Gentamisin ve tobramisin ortopedik enfeksiyonlarda sement içi antibiyotik uygulamalarında sıkça kullanılmaktadır. ${ }^{[22]}$

Aminoglikozitler enzimatik modifikasyon ile inaktive edilebilir. Amikasin diğer aminoglikozit türlerine göre daha az inaktive edilebilmektedir. Bu nedenle amikasine duyarlı suşlar diğer aminoglikozitlere duyarlı olanlardan daha fazladır. ${ }^{[21]}$ Yan etki olarak nefrotoksik ve ototoksik olabilir.

\section{Rifampisin}

Rifampisin birçok gram (+) ve gram (-) bakteriye karşı bakterisidal etkilidir. Oldukça aktif bir antistafilokokal ajandır. ${ }^{[8]}$ Ancak gram (-) bakterilere karşı aminoglikozitlerden daha az etkilidir. Bakteriyel enfeksiyonların tedavisinde tek başına kullanıldığında hızla direnç gelişebilir ve MRSA'nın etken olduğu kemik enfeksiyonlarında vankomisin ve rifampisin kombinasyonunu önerilmektedir. ${ }^{[23]}$ Rifampisine direnç gelişmesini engellemek için başka bir antibiyotik ile kombine kullanılabilir.

Rifampisinin yan etkilerine bakıldığında vücut sıvılarında kırmızı-turuncu renk değişikliği, gastrointestinal semptomlar, hepatit ve hafif immunosupresyon sayılabilir. ${ }^{[24]}$ İzoniazid ile beraber kullanıldığında belirgin hepatotoksik etki oluşturur.

\section{Florokinolonlar}

Kinolonların 3. jenerasyonunu oluşturur ve dört alt gruptan meydana gelir. Birinci jenerasyon florokinolonlar üriner enfeksiyonlarda kullanılırken 2. 3. ve 4. jenerasyon florokinolonlar osteomiyelit gibi kas-iskelet sistemi enfeksiyonlarında kullanılabilir. ${ }^{[25]}$

íkinci nesil florokinolonlar (siprofloksasin, ofloksasin) yeterli serum, doku, üriner konsantrasyona ulaşır ve gram negatif organizmalara karşı etkilidir. Birçok streptokokal tür ve anaerobik organizma 2. nesil florokinolonlara dirençlidir. Bazı S.aureus ve S.epidermidis türlerinde de direnç olduğu bildirilmiştir. Siprofloksasin özellikle gram negatif bakterilerin neden olduğu kemik enfeksiyonlarında uzun süreli parenteral tedavi olarak kullanılabilir. ${ }^{[8]}$

Üçüncü nesil florokinolonlar (levofloksasin, sparfloksasin) streptekok türleri, penisiline orta derecede dirençli suşlar ve dirençli streptekok pnemoniaya etkilidir. Gram negatif organizmaların çoğuna karşı da etkinliği vardır. ${ }^{[8]}$

Dördüncü nesil florokinolonlar (trovafloksasin) aerobik gram pozitif ve gram negatif bakterilere karşı etkilidir. Etkinlik olarak 3. nesile benzer. Ancak anerobik bakterilere karşı etkinliği daha iyidir.[25] Trovafloksasinde iki haftadan uzun süren tedavide ciddi karaciğer yetmezliği ve ölüm bildirilmiştir. Bu nedenle trovafloksasin sadece çok ciddi ekstremite yaralanması veya hayatı tehdit eden enfeksiyon varlığında kullanılabilir.

İkinci ve 3. nesil florokinolonlara karşı direnç giderek artmaktadır. ${ }^{[25]}$

Florokinolonların parenteral uygulaması kadar oral uygulamasında da serum konsantrasyonları oldukça iyidir. Bu da hastanede kalış süresini azaltır. Sıklıkla tedavi parenteral başlar ve oral devam eder.

Puberteyi tamamlamamış çocuklarda kullanılması uygun değildir. Kemik gelişimini olumsuz etkileyebilir. ${ }^{[25]}$ Hastaların \%2-5'inde bulantı, kusma ve dispepsi şikâyetlerine yol açar. Hastaların \%1-2'sinde ise merkezi sinir sistemi reaksiyonları, baş ağrısı, baş dönmesi, yorgunluk ve uykusuzluk yapabilir. Kinolonlar tendinite neden olabilir, aşil tendon rüptürüne yol açabilir.

\section{Trimetoprim-Sulfometaksazol}

Trimetoprim ve sulfonamid kombinasyonundan oluşmuştur. E.coli, P.mirabilis, H.influenzae, S.maltophilia'ya karşı etkilidir. Ayrıca K.pneumoniae, Enterobacter türleri, S.marcescens, Proteus, ve P.aeroginosa türlerine karşı da etkilidir. ${ }^{[8]}$ Trimetoprim-sulfametoksazolun birincil hedefi aerobik gram (-) bakterilerdir, ancak S.aureus, S.pneumoniae ve S.pyogenes türlerine de etkilidir. ${ }^{[26]}$ Özellikle metisilin dirençli S.aureus ve S.epidermidis enfeksiyonlarında rifampisin ile kombine kullanılabilir. ${ }^{[26]}$ Ayrıca trimetoprim-sulfometaksazol osteomiyelit için supresif tedavi de sağlamaktadır.

Yan etkilerine bakıldığında gastrointestinal yan etkiler, nefrotoksisite, akut hemolitik anemi, glikoz 6 fosfat dehidrogenaz defisiti, agranülositoz, aplastik anemi ve trombositopeni oluşturabilir. ${ }^{[26]}$

\section{Nitroimidazoller}

Bu grupta metronidazol, ornidazol, tinidazol, seknidazol ve nimorazol bulunur. Anaerobik bakterilerin tedavisinde kullanılır. Güçlü bakterisidal etkinliği vardır. Non-spesifik bir elektron tuzağı gibi anaerob bakterilerdeki elektronları kendine çeker. Böylece bakterideki enerji üretimini bozar. Ayrıca bakterideki DNA sentezini inhibe eder. ${ }^{[8]}$

Metronidazol; aktinomiçes ve mikroaerofilik streptokok hariç tüm gram negatiflere etkilidir. ${ }^{[27]}$ ilaç iyi emilir ve doku ve abse içine güçlü bir şekilde nüfuz eder.

Yan etkileri nadirdir. En sık ağızda metalik tat görülür. Epileptik nöbet, alkol ile alınınca disülfiram benzeri 
reaksiyon, psödomembranöz kolit, ishal, karın ağrısı ve pankreatit yapabilir.

\section{Linezolid}

Geniş etki spektrumu olup, in-vitro gram $\left(^{+}\right) \mathrm{di}-$ rençli mikroorganizmalara, metisiline dirençli S.aureus (MRSA), vankomisine dirençli E.faecalis ve vankomisine dirençli E.faecium (VRE)'a etkilidir. ${ }^{[28]}$

Linezolidin kemik ve kas konsantrasyonları eş zamanlı serum konsantrasyonlarıyla karşılaştırıldığında $\% 60$ ve \%94'tür. Yumuşak doku ve vezikül sıvısına da penetrasyonu çok iyi olup, doku konsantrasyonu kan konsantrasyonundan daha iyidir. Çoklu dirençli MRSA enfeksiyonlarında, dokuda kan akımının bozulması durumunda bile rahatlıkla kullanılabileceği gösterilmiştir. ${ }^{[28]}$ Diyabetik ayak enfeksiyonlarında linezolidin klinik etkinliğinin vankomisin ile benzer olduğu, aminopenisilin/beta-laktamaz inhibitörlerinden farklı olmadığı gösterilmiştir. ${ }^{[29]}$

Linezolid aynı zamanda MRSA ilişkili deri ve yumuşak doku enfeksiyonları ile cerrahi enfeksiyonların tedavisinde de vankomisinle karşılaştırılmıştır. Çalışmada klinik ve bakteriyolojik etkinlik vankomisinden üstün bulunmuştur. ${ }^{[29]}$

Hem çocuklarda hem de erişkinlerde güvenilir bir ilaçtır. Linezolid esas olarak bakteriostatik etkilidir.

Klinik çalışmalarda linezolid güvenilir bir ilaç olarak gösterilmiştir. En sık rastlanılan yan etkileri ishal, kusma ve baş ağrısıdır.

\section{Daptomisin}

Komplike deri ve yumuşak doku enfeksiyonları, S.aureus'un etken olduğu bakteriyemi ve sağ kalp enfektif endokarditi için kullanılır. Hızlı bakterisidal etkinliğe sahiptir. ${ }^{[30,31]}$

Daptomisin genelde tolere edilebilir ve ılımlı yan etkileri olan bir ilaç olarak karşımıza çıkmaktadır. Düşük yan etki profili ile güvenli bir molekül olmakla birlikte ilaç düzey takibi gerekmemektedir. ${ }^{[30]}$ En sık bildirilen yan etkiler başta konstipasyon olmak üzere gastrointestinal yan etkilerdir (ishal, kusma, bulantı). Bunun yanında; anemi, hipokalemi, baş ağrısı, artralji, periferal ödem ve renal bozukluk da yapabilir.

\section{Fosfomisin}

Geniş antimikrobiyal spektruma sahip özgül bir antibiyotiktir. Fosfomisin, metisiline dirençli S.aureus, glikopeptidlere duyarlı veya dirençli enterokoklar gibi gram (+) bakterilere karşı etkilidir. Ayrıca birçok antibiyotiğe dirençli Enterobacter, Klebsiella, Citrobacter,
Proteus, Salmonella cinslerine ait türler ile E.coli gibi gram (-) patojenlerin çoğuna karşı hızlı bakterisidal aktiviteye sahiptir. ${ }^{[32]}$

Gram (-) basillere (P.aeruginosa suşları hariç) karşı etkindir. İn vitro çalışmalarda, fosfomisinin bir grup beta-laktam antibiyotikler, aminoglikozidler ve diğer bazı ajanlar ile birlikte kullanılmasının, solunum, dolaşım ve üriner sistem enfeksiyonlarının bakteriyel etkenlerine karşı sinerji oluşturduğu gösterilmiştir. ${ }^{[32]}$

Tüm yan etkilerin genellikle hafif düzeyde olup ve fosfomisinin genellikle iyi tolere edildiği anlaşılmaktadır. En sık görülen yan etki, öncelikle ishal (\%4) olmak üzere geçici bulantı $(\% 2,2)$ ve epigastrik/abdominal ağrının $(\% 1,3)$ eşlik ettiği hafif, kendini sınırlayan ve iyi tolere edilebilen gastrointestinal rahatsızlıklardır. ${ }^{[32]}$

\section{SIK GÖRÜLEN ORTOPEDIK PATOLOJILERDE ANTIBIYOTIK KULLANIMI NASIL OLMALIDIR?}

Genel olarak antibiyotik kullanımı kültür sonuçlarına göre yapılmalıdır. Tablo 1-3'te ortopedi ve travmatoloji alanında sıkça görülen suşlara karşı hangi antibiyotiğin veya kombinasyonların kullanılması gerektiği gösterilmiştir.

\section{Selülit ve Erizipel}

Erizipel üst dermisin ve yüzeyel lenfatiklerin enfeksiyonudur. En sık etken A grubu beta-hemolitik streptokoklardır. Fakat C ve G grubu streptokoklar, S.aureus, nadiren de $B$ grubu streptokoklar etken olabilir. Erizipel cildin akut enfeksiyonudur. Selülitte, erizipelden farklı olarak subkutan ve derin doku tutulumu görülür. Etken çoğunlukla A grubu beta-hemolitik streptokoklardır. Fakat farklı etkenler de çeşitli risk faktörleri varlığında selülit etyolojisinden sorumlu olabilir (S.aureus, B grubu streptekoklar, P.aeruginosa, Pasteruella, H.cinadi).

Kas-iskelet sistemi enfeksiyonları arasında selülit ve erizipel kısa süreli antibiyotik tedavisine ihtiyaç duyar (10-14 gün). ${ }^{[33]}$ Parenteral tedavi, hasta klinik olarak stabil olduğunda oral tedaviye dönüştürülebilir. Erizipel daha yüksek nüks oranına sahiptir ve daha uzun süreli paranteral tedaviye gerek duyulabilir.

\section{Septik Artrit}

Septik artrit aspirasyon, artroskopik veya açık debridmanı takiben 2-3 haftalık parenteral antibiyotik verilerek tedavi edilir. ${ }^{[34]} \mathrm{H}$.influenzae, streptokok türleri, ve $N$.gonore nedeni ile oluşan septik artrit olgularında iki haftalık tedavi yeterlidir. Ancak S.aureus ve gram (-) basillerin neden olduğu daha dirençli enfeksiyonlarda üç haftalık tedavi tercih edilir. ${ }^{[34]}$ 
Tablo 1. Anaerobik bazı organizmalar: tedavide ilk antibiyotik seçimi (erişkin dozları) ${ }^{[8]}$

\begin{tabular}{lll}
\hline Organizma & Ilk tercih antibiyotik & Alternatif antibiyotikler \\
\hline - Bacteroides fragilis & $\begin{array}{l}\text { Klindamisin (her } 8 \text { saatte } 900 \mathrm{mg} \text { ) veya } \\
\text { Metrodinazol (her } 8 \text { saatte } 500 \mathrm{mg})\end{array}$ & Ampisilin-sulbaktam, tikarsilin-klavulanat \\
- Clostridium türleri & $\begin{array}{l}\text { Klindamisin (her } 8 \text { saatte } 900 \mathrm{mg}) \text { veya } \\
\left.\text { Penisilin G (her } 4 \text { saatte } 2 \times 10^{6} \mathrm{U}\right)\end{array}$ & Ampisilin-sulbaktam, metrodinazol
\end{tabular}

Tablo 2. Gram pozitif bazı organizmalar: tedavide ilk antibiyotik seçimi (erişkin dozları) ${ }^{[7,8]}$

\begin{tabular}{|c|c|c|}
\hline Organizma & Illk tercih antibiyotik & Alternatif antibiyotikler \\
\hline \multicolumn{3}{|l|}{ Metisilin duyarlı } \\
\hline - Staphilococcus aureus & $\begin{array}{l}\text { Nafsilin (her } 4 \text { saatte } 2 \mathrm{~g} \text { ) veya } \\
\text { Klindamisin (her } 8 \text { saatte } 900 \text { mg) }\end{array}$ & Sefazolin veya vankomisin \\
\hline - Koagülaz negatif Stafilokok türleri & $\begin{array}{l}\text { Nafsilin (her } 6 \text { saatte } 2 \mathrm{~g} \text { ) veya } \\
\text { Klindamisin (her } 8 \text { saatte } 900 \mathrm{mg} \text { ) }\end{array}$ & Sefazolin veya vankomisin \\
\hline \multicolumn{3}{|l|}{ Metisilin dirençli } \\
\hline - Staphilococcus aureus & $\begin{array}{l}\text { Vankomisin (her } 12 \text { saatte } 1 \mathrm{~g} \text { ) veya } \\
\text { Linezolid (her } 12 \text { saatte } 600 \mathrm{mg} \text { ) }\end{array}$ & $\begin{array}{l}\text { Trimetoprim-sulfametoksazo } \\
\text { içeren veya içermeyen minosi }\end{array}$ \\
\hline - Koagülaz negatif Stafilokok türleri & $\begin{array}{l}\text { Vankomisin (her } 12 \text { saatte } 1 \mathrm{~g} \text { ) veya } \\
\text { Linezolid (her } 12 \text { saatte } 600 \mathrm{mg} \text { ) }\end{array}$ & $\begin{array}{l}\text { Trimetoprim-sulfametoksazo } \\
\text { içeren veya içermeyen minosi }\end{array}$ \\
\hline - A grubu Streptokok veya Streptococcus pyogenes & $\begin{array}{l}\text { Penisilin G (her } 4 \text { saatte } 2 \times 10^{6} \mathrm{U} \text { ) veya } \\
\text { Ampisilin (her } 6 \text { saatte } 2 \mathrm{~g} \text { ) }\end{array}$ & Klindamisin, sefalosporin vey \\
\hline - B grubu Streptokok veya Streptococcus agalactia & $\begin{array}{l}\text { Penisilin G (her } 4 \text { saatte } 2 \times 10^{6} \mathrm{U} \text { ) veya } \\
\text { Ampisilin (her } 6 \text { saatte } 2 \mathrm{~g} \text { ) }\end{array}$ & Klindamisin, sefalosporin vey \\
\hline \multicolumn{3}{|l|}{ Duyarlı } \\
\hline - Enterekok türleri & $\begin{array}{l}\text { Ampisilin (her } 6 \text { saatte } 1 \mathrm{~g} \text { ) veya } \\
\text { Vankomisin (her } 12 \text { saatte } 1 \mathrm{~g} \text { ) }\end{array}$ & Ampisilin-sulbaktam linezolic \\
\hline \multicolumn{3}{|l|}{ Dirençli } \\
\hline - Enterecoccus faecium & $\begin{array}{l}\text { Kinopristin/Dalfopristin } \\
\text { (her } 8 \text { saatte } 7,5 \mathrm{mg} / \mathrm{kg} \text { ) veya } \\
\text { Linezolid (her } 12 \text { saatte } 600 \mathrm{mg} \text { ) }\end{array}$ & Kloramfenikol ve rifampin \\
\hline
\end{tabular}

Tablo 3. Gram (-) bazı organizmalar: tedavide ilk antibiyotik seçimi (erişkin dozları) ${ }^{[7,8]}$

\begin{tabular}{|c|c|c|}
\hline Organizma & ilk tercih antibiyotik & Alternatif antibiyotikler \\
\hline - Acinetobacter türleri & $\begin{array}{l}\text { Seftazidim (her } 8 \text { saatte } 1 \mathrm{~g} \text { ) ve levofloksasin } \\
\text { ( } 500 \mathrm{mg} / \mathrm{gün} \text { ) veya imipenem (her } 6 \text { saatte } 500 \mathrm{mg} \text { ) }\end{array}$ & Ampisilin-sulbaktam \\
\hline - Enterobacter türleri & $\begin{array}{l}\text { Sefotaksim (her } 6 \text { saatte } 1 \mathrm{~g} \text { ) veya } \\
\text { imipenem (her } 6 \text { saate } 500 \mathrm{mg} \text { ) }\end{array}$ & $\begin{array}{l}\text { Levofloksasin, mezlosilin veya } \\
\text { tikarsilin-klavulanat }\end{array}$ \\
\hline - Escherichia coli & Ampisilin-sulbaktam (her 6 saatte $3 \mathrm{~g}$ ) & $\begin{array}{l}\text { Sefazolin, levofloksasin, gentamisin veya } \\
\text { trimetoprim-sulfametoksazol }\end{array}$ \\
\hline - Klebsiella türleri & $\begin{array}{l}\text { Sefotaksim (her } 6 \text { satte } 1 \mathrm{~g}) \text { veya } \\
\text { levofloksasin }(500 \mathrm{mg} / \mathrm{gün})\end{array}$ & Ampisilin-sulbaktam veya gentamisin \\
\hline - Proteus mirabilis & $\begin{array}{l}\text { Ampisilin (her } 6 \text { saatte } 1 \mathrm{~g} \text { ) veya } \\
\text { levofloksasin }(500 \mathrm{mg} / \text { gün })\end{array}$ & $\begin{array}{l}\text { Sefazolin, trimetoprim-sulfametoksazol veya } \\
\text { gentamisin }\end{array}$ \\
\hline - Neisseria gonore & $\begin{array}{l}\text { Seftriakson ( } 125 \mathrm{mg} \text { 'lık bir intramusküler enjeksiyon) ve } \\
\text { azitromisin ( } 1 \mathrm{~g} \text { oral yoldan tek doz) }\end{array}$ & Levofloksasin ve azitromisin \\
\hline - Pseudomonas aeuriginosa & $\begin{array}{l}\text { Sefepim + (her } 12 \text { saatte } 12 \text { gram) veya } \\
\text { piperasilin + (her } 6 \text { saatte } 3 \mathrm{~g} \text { ) veya } \\
\text { imipenem (her } 6 \text { saatte } 500 \mathrm{mg} \text { ) }\end{array}$ & $\begin{array}{l}\text { Tikarsilin-klavulanat, tobramisin, amikasin veya } \\
\text { siprofloksasin }\end{array}$ \\
\hline
\end{tabular}




\section{Osteomiyelit}

Osteomiyelit iyi bir debridman sonrası genellikle 4-8 hafta parenteral antibiyotik ile tedavi edilir. Bu konudaki en iyi veriler hayvan modellerinden elde edilmiştir. Ancak antibiyotik tedavisinin optimal süresi net bir şekilde belirlenmemiştir. ${ }^{[35]}$

Osteomiyelit tedavisindeki önemli noktalardan birisi parenteral tedaviden oral tedaviye geçiş zamanıdır. Swiontkowski ve ark.'nın yaptığı çalışmada, 93 hastaya cerrahi müdahale sonrası yedi günlük parenteral tedaviyi takiben altı hafta oral antibiyotik tedavisi verilmiş. Tedavinin \%91 oranında (87 hasta) başarılı olduğu bildirilmiştir. ${ }^{[36]}$ Shirtliff ve ark.'nın uzun kemik osteomiyelitlerinde yaptıkları karşılaştırmalı çalışmada dört hafta parenteral tedavi ile iki hafta parenteral tedavi + dört hafta oral tedavi karşılaştırılmıştır. Sadece parenteral tedavi alan grupta başarı \%84,3 iken parenteral ve oral tedavi alan grupta $\% 89,5$ olarak bulunmuştur. ${ }^{[37]}$

Uzun kemik osteomiyelit tedavisinde antibiyotik tedavisi süresi için geçerli öneri 4-6 haftadır. Çocuklara iki haftalık parenteral terapi ve ardından dört haftalık oral terapi verilir. Yetişkinler için geleneksel tedavi 4-6 hafta parenteral terapidir. Ancak, birçok merkezde iki haftalık parenteral terapi ve ardından 4-6 haftalık oral terapi kullanılmaktadır.

\section{Diyabetik Ayaklarda Osteomiyelit}

Diyabetik ayak osteomiyelit antibiyotik tedavi süresi genellikle cerrahi tedavi türüne dayanmaktadır. ${ }^{[38]}$ Cerrahi tedavi mümkün olmadığında veya kabul edilmediğinde, hastaya uzun süreli oral antibiyotik terapisi ile baskılayıcı tedavi uygulanabilir.

Osteomiyelitli kemik debridman için uygunsa, debridman sonrası 4-6 hafta antibiyotik tedavisi verilir. Hastaya ablatif tedavi uygulandığında ve osteomiyelit içeren tüm kemik doku çıkarıldığında, rezidü yumuşak doku enfeksiyonunun tedavisi için iki hafta boyunca antibiyotik uygulanır.

Amputasyon enfeksiyon bölgesine uzak yapıldığında, genellikle üç günden az antibiyotik tedavisi yeterlidir. Bazen, ayak osteomiyeliti olan bir diyabetik hasta enfeksiyonun ortadan kaldırılması için uzun vadeli oral antibiyotik tedavisi ile takip edilir. Bu sadece osteitis (kemik dış korteks tutulumu) tedavisi için mümkündür. Uzun süreli antibiyotik tedavisi ile tam kalınlıkta osteomiyelit eradikasyonu muhtemelen mümkün değildir.

\section{KAYNAKLAR}

1. Cook GE, Markel DC, Ren W, Webb LX, McKee MD, Schemitsch EH. Infection in orthopaedics. J Orthop Trauma 2015;29:S19-23. Crossref
2. Tribble DR, Conger NG, Fraser S, Gleeson TD, Wilkins K, Antonille T, Weintrob A, Ganesan A, Gaskins LJ, Li P, Grandits G, Landrum ML, Hospenthal DR, Millar EV, Blackbourne LH, Dunne JR, Craft D, Mende K, Wortmann GW, Herlihy R, McDonald J, Murray CK. Infection-associated clinical outcomes in hospitalized medical evacuees following traumatic injury trauma infectious disease outcome study. J Trauma 2011;71(Suppl):S33. Crossref

3. Dodwell ER. Osteomyelitis and septic arthritis in children: Current concepts. Curr Opin Pediatr 2013;25(1):58-63. Crossref

4. Blyth MJ, Kincaid R, Craigen MA, Bennet GC. The changing epidemiology of acute and subacute haematogenous osteomyelitis in children. J Bone Joint Surg Br 2001;83(1):99102. Crossref

5. Richards JE, Kauffmann RM, Obremskey WT, May AK. Stress-induced hyperglycemia as a risk factor for surgicalsite infection in non-diabetic orthopaedic trauma patients admitted to the intensive care unit. J Orthop Trauma 2013;27(1):16. Crossref

6. Landersdorfer CB, Bulitta JB, Kinzig M, Holzgrabe U, Sörgel $F$. Penetration of antibacterials into bone: pharmacokinetic, pharmacodynamic and bioanalytical considerations. Clin Pharmacokinet 2009;48(2):89-124. Crossref

7. Thabit AK, Fatani DF, Bamakhrama MS, Barnawi OA, Basudan LO, Alhejaili SF. Antibiotic penetration into bone and joints: an updated review. Int J Infect Dis 2019;81:12836. Crossref

8. Mader JT, Wang J, Calhoun JH. Antibiotic therapy for musculoskeletal infections. J Bone Joint Surg Am 2001;83(12):1878-90.

9. Neugut Al, Ghatak AT, Miller RL. Anaphylaxis in the United States: an investigation into its epidemiology. Arch Intern Med 2001;161(1):15-21. Crossref

10. Har D, Solensky R. Penicillin and beta-lactam hypersensitivity. Immunol Allergy Clin North Am 2017;37(4):643-62. Crossref

11. Kavanagh N, Ryan EJ, Widaa A, Sexton G, Fennell J, O'rourke S, Kerrigan SW. Staphylococcal osteomyelitis: disease progression, treatment challenges, and future directions. Clin Microbiol Rev 2018;31(2):e00084-17. Crossref

12. Eckburg PB, Lister $T$, Walpole S, Keutzer T, Utley L, Tomayko J, Kopp E, Farinola N, Coleman S. Safety, Tolerability, Pharmacokinetics, and Drug Interaction Potential of SPR741, an Intravenous Potential or after Single and Multiple Ascending Doses and When Combined with $\beta$-Lactam Antibiotics in Healthy Subjects. Antimicrob Agents Chemother 2019;63(9):e00892-19. Crossref

13. Sader HS, Mendes RE, Pfaller MA, Shortridge D, Flamm RK, Castanheira M. Antimicrobial activities of aztreonamavibactam and comparator agents against contemporary (2016) clinical Enterobacteriaceae isolates. Antimicrob Agents Chemother 2017;62(1):e01856-17. Crossref

14. Loubet $P$, Burdet $C$, Vindrios W, Grall N, WolffM, Yazdanpanah $\mathrm{Y}$, Lescure FX. Cefazolin versus anti-staphylococcal penicillins for treatment of methicillin-susceptible Staphylococcus aureus bacteraemia: a narrative review. Clin Microbiol Infect 2018;24(2):125-32. Crossref

15. Scully BE, Neu HC. Clinical efficacy of ceftazidime. Treatment of serious infection due to multiresistant Pseudomonas and other gram-negative bacteria. Arch Intern Med 1984;144(1):57-62. Crossref

16. Alvarez R, Cortes LEL, Molina J, Cisneros JM, Pachón J. Optimizing the clinical use of vancomycin. Antimicrob Agents Chemother 2016;60(5):2601-9. Crossref 
17. O'Driscoll T, Crank CW. Vancomycin-resistant enterococcal infections: epidemiology, clinical manifestations, and optimal management. Infect Drug Resist 2015;8:217-30. Crossref

18. Le FrockJL, Klainer AS, Chen S, Gainer RB, Omar M, Anderson $W$. Thespectrum of colitis associated with lincomycin and clindamycin therapy. J Infect Dis 2005;131(Suppl):S108-15. Crossref

19. Westphal JF. Macrolide-induced clinically relevant drug interactions with cytochrome P-450A(CYP)3A4: an update focused on clarithromycin, azithromycin and dirithromycin. Br J Clin Pharmacol 2000;50(4):285-95. Crossref

20. Phillips OA, Sharaf LH. Oxazolidinone antimicrobials: a patent review (2012-2015). Expert Opin Ther Pat 2016;26(5):591-605. Crossref

21. Tanyel E. Aminoglikozidler. Turkiye Klinikleri J Inf Dis - Special Topics 2017;10(1):66-70.

22. Vrabec G, Stevenson W, Elguizaoui S, Kirsch M, Pinkowski J. What is the intraarticular concentration of tobramycin using low-dose tobramycin bone cement in TKA.an in vivo analysis? Clin Orthop Relat Res 2016;474(11):2441-7. Crossref

23. Gemmell CG, Edwards DI, Fraise AP, Gould FK, Ridgway GL, Warren RE. Guidelines for the prophylaxi and treatment of methicillin-resistant Staphylococcus aureus (MRSA) infections in the UK. J Antimicrob Chemother 2006;57(4):589-608. Crossref

24. Bliziotis IA, Ntziora F, Lawrence KR, Falagas ME. Rifampin as adjuvant treatment of Gram-positive bacterial infections: a systematic review of comparative clinical trials. Eur J Clin Microbiol Infect Dis 2007;26(12):849-56. Crossref

25. Owens RC, Ambrose PG. Antimicrobial safety: Focus on fluoroquinolones. Clin Infect Dis 2005;41(Suppl 2):S144-57. Crossref

26. Aktas F. Sulfonamidler, Trimetoprim ve Trimetoprim/ Sulfametoksazol. Turkiye Klinikleri J Inf Dis - Special Topics 2017;10(1):117-20.

27. Rosenblatt JE, Edson RS. Metronidazole. Mayo Clin Proc 1983;58:154-7.
28. Rao N, Ziran BH, Wagener MM, Santa ER, Yu VL. Similar hematologic effects of long-term linezolid and vancomycin therapy in a prospective observational study of patients with orthopedic infections. Clin Infect Dis 2004;38(8):1058-64. Crossref

29. Wunderink RG, Rello J, Cammarata SK, Croos Dabrera $\mathrm{RV}$, Kollef $\mathrm{MH}$. Linezolid vs vancomycin: analysis of two double blind studies of patients with methicillin-resistant Staphylococcus aureus nosocomial pneumonia. Chest 2003;124(5):1789-97. Crossref

30. Carpenter CF, Chambers HF. Daptomycin: another novel agent for treating infections due to drug-resistant grampositive pathogens. Clin Infect Dis 2004;38(7):994-1000. Crossref

31. Friedman L, Alder JD, Silverman JA. Genetic changes that correlate with reduced susceptibilit to daptomycin in Staphylococcus aureus. Antimicrob Agents Chemother 2006;50(6):2137-45. Crossref

32. Falagas ME, Giannopoulou KP, Kokolakis GN, Rafailidis PI. Fosfomycin: use beyond urinary tract and gastrointestinal infections. Clin Infect Dis 2008;46(7):1069-77. Crossref

33. Dryden MS. Skin and soft tissue infection: microbiology and epidemiology. Int J Antimicrob Agents 2009;34:S2-7. Crossref

34. Mathews CJ, Weston VC, Jones A, Field M, Coakley G. Bacterial septic arthritis in adults. Lancet 2010;375(9717):846-55. Crossref

35. Calhoun JH, Manring MM. Adult osteomyelitis. Infect Dis Clin North Am 2005;19(4):765-86. Crossref

36. Swiontkowski MF, Hanel DP, Vedder NB, Schwappach JR. A comparison of short- and long-term intravenous antibiotic therapy in the postoperative management of adult osteomyelitis. J Bone Joint Surg Br 1999;81-B(6):1046-50. Crossref

37. Shirtliff ME, Mohan D, Calhoun JH, Mader JT. Four-week intravenous antibiotic therapy versus two-week intravenous antibiotic therapy versus two-week intravenous plus fourweek oral antibiotic therapy in the treatment of long bone osteomyelitis. Snowmass CO: Annual Meeting of the Musculoskeletal Infection Society; 1997. p.13-6.

38. Mader JT, Calhoun J. Osteomyelitis. In: Mandell GL, Bennett JE, Dolin R, editors. Mandell, Douglas, and Bennett's principles and practice of infectious diseases, 5th ed. Philadelphia: Churchill Livingstone; 2000. p.1039-51. 